\title{
The Course Reform of Digital Signal Processing for Engineering Education
}

\author{
Guo Luo, Lihua Huang, Xiaohong Zhan, Jiesheng Ye \\ School of Electrical and Computer Engineering \\ Nanfang College of Sun Yat-Sen University \\ Guangzhou, China \\ e-mail: 185616509@qq.com
}

\begin{abstract}
Digital Signal Processing (DSP) is a widely used subject in the application of engineering. However, in undergraduate teaching process, the derivation of mathematical formula and its physical meaning are outside of students' faculties of sense. For the beginners, mathematical concepts are hard for them to thoroughly understand, not to mention physical meaning and engineering concepts. Further more, this situation will directly make students lack of understanding about the essence and usages of DSP course. In the background of engineering education, it is necessary to reform the teaching method of DSP course. In view of different teaching contents and requirements, the teaching task of DSP course is completed by combining with theoretical teaching and experimental demonstration. The reform of theory teaching mainly consists of three parts: teaching contents, teaching methods and teaching form. In order to internalize knowledge and stimulate students' interest in DSP course, the engineering practice reform of experimental teaching is introduced into engineering application cases, which applies theoretical knowledge to process actual signals. The teaching reform practice results show that the teaching quality of DSP has been greatly improved. Students can process actual engineering signals after learning this course.
\end{abstract} reform;

Keywords- digital signal processing; engineering education;

\section{INTRODUCTION}

Digital Signal Processing (DSP) is an important fundamental course for the students in the Department of Electrical Engineering [1]. The course of signal and system is its first course and its extended curriculum is communication fundamentals course. In the course of DSP, course contents require higher level of teachers' ability, as it involves not only basic theories and algorithms, but also the wide coverage of hardware circuits. The teaching method of pure theory will be not suitable for students, especially in the background of engineering education, the demands for students' application ability are getting higher and higher [2]. Based on the requirements of engineering education, aiming at training innovative talents and cultivating students' ability to analyze and solve problems, this paper explores effective teaching methods in DSP course. Through the reform of teaching methods, we change the guiding ideology of teaching into student-oriented, change the traditional way of learning of students, mobilize the enthusiasm of the students, stimulate students' interest in improving the ability of engineering design, integrate DSP course with some other engineering application course such as microcomputer, digital circuit technology and embedded system.

We carry out the reform of DSP course in three aspects.

- In the teaching of theory, the aim of curriculum teaching is adjusted to emphasize the cultivation of engineering accomplishment, innovation spirit and practical ability. According to the requirements of training objectives for undergraduate students, we strengthen the foundation, emphasize practice, enhance ability and improve quality. According to different teaching contents, we should mobilize students' enthusiasm and initiative by inspiring way, stimulate students' interest in DSP course learning, and improve the students' ability of analyzing and solving problems.

- In experimental teaching, we adopt the engineering practice mode that is combining engineering cases with theory, so that students can learn some application software to solve engineering problem with integrating different subjects.

- $\quad$ Taking the learning process and learning outcomes as the guiding ideology, combining with the teaching process and teaching objective management, we build up a comprehensive evaluation system for extracurricular autonomous learning.

\section{REFORM OF THEORETICAL TEACHING}

\section{A. Reform the Teaching Method}

The traditional teaching methods are mainly focused on the blackboard. Writing on the blackboard can be clearly presented algorithm, students can quickly grasp the theoretical conclusions. However, all the blackboard writing methods will make students regard this course as a mathematics course rather than DSP course. Only grasping the derivation process and deducing the conclusions, regardless its extended physical meaning, this situation will not build up students' engineering quality to process the actual signal. We use blackboard, multimedia courseware, simulation program and flash animation for enriching 
curriculum expression. The contents are mainly based on multimedia courseware. Combining with blackboard writing, when some important algorithms encounter, Matlab simulation program is also embedded to demonstrate.

Partial theoretical contents are consolidated by flash animation. For example, after multimedia and blackboard instruction, the sampling of continuous time signal and its reconstruction are used to display the whole signal processing by using flash animation. The teaching means adopt various ways to arouse the students' participation in the DSP course.

\section{B. Teaching Model}

Detailed instruction, classroom discussion, students' self-study with PPT presentation and monographic study are included in teaching model of DSP course. The course contents arrangement is shown in the Table 1 .

TABLE I.

COURSE CONTENTS ARRANGEMENT

\begin{tabular}{|c|c|}
\hline $\begin{array}{l}\text { Teaching } \\
\text { Model }\end{array}$ & Course Contents \\
\hline \multirow{4}{*}{$\begin{array}{l}\text { Detailed } \\
\text { Instruction }\end{array}$} & Linear shift invariant system \\
\hline & $\mathrm{Z}$ transformation \\
\hline & Discrete Fourier transform \\
\hline & $\begin{array}{c}\text { Fast Fourier transform(Cooley Tukey algorithm and } \\
\text { Sander Tukey algorithm) }\end{array}$ \\
\hline \multirow{3}{*}{$\begin{array}{l}\text { Monographic } \\
\text { Study }\end{array}$} & Convolution \\
\hline & $\begin{array}{l}\text { Sampling and sampling recovery of continuous time } \\
\text { signals and } \mathrm{Z} \text { transform of sequence }\end{array}$ \\
\hline & Design of IIR filter and design of FIR filter \\
\hline \multirow{3}{*}{$\begin{array}{l}\text { Classroom } \\
\text { Discussion }\end{array}$} & The symmetric properties of Fourier transformation \\
\hline & Frequency domain sampling theorem \\
\hline & $\begin{array}{c}\text { The characteristics of linear convolution and linear } \\
\text { phase FIR filter }\end{array}$ \\
\hline \multirow{2}{*}{$\begin{array}{l}\text { Self-study with } \\
\text { PPT } \\
\text { Presentation }\end{array}$} & $\begin{array}{c}\text { Linear difference equation with constant } \\
\text { coefficients }\end{array}$ \\
\hline & The design case of digital filter \\
\hline
\end{tabular}

In particular, self-study and giving the presentation of its learning results in the form of PPT can make students more active in the classroom, which also gives students an opportunity to show themselves. At the same time, PPT score will account for $10 \%$ of students' final grade.

\section{REFORM OF EXPERIMENTICAL TEACHING}

As a powerful tool, MATLAB is necessary to introduce into digital signal processing teaching, which can make students understand the abstract content intuitively[3]. The purpose of experimental teaching is to enable students to master the basic theory and algorithm design idea of DSP, apply spectrum analysis and design filter to signal preprocessing in practical engineering requirement.

First of all, students will start from understanding simple algorithm to program by using MATLAB software, just taking sequence production, addition or multiplication as examples. Secondly, applying wavread function to record voice signal and using FFT transform to show its frequency distribution are basic experimental example, which are convenient for students to operate in the laboratory. Finally, raw diaphragmatic electromyographic (EMGdi) is used as signal processing object, and electrocardiogram is its background noise. As the criterion of biomedical signal engineering application, students are required to remove ECG noise and extract EMGdi signal.

\section{A. Experimental Material}

Clinical EMGdi experimental data were collected from patients with lung illness in Guangzhou Institute of Respiratory Diseases with duration of 15 seconds. EMGdi signal acquisition hardware system consists of five lead esophagus electrode and Powerlab medical physiological signal acquisition system provided by Australia ADInstruments Company. EMGdi signal is amplified 1000 times and then passes a series of filter such as $50 \mathrm{~Hz}$ bandstop filter, $15 \mathrm{~Hz}$ high pass filter and $1000 \mathrm{~Hz}$ low pass filter. The sample frequency of system is $2000 \mathrm{~Hz}$. Raw EMGdi signal is shown as Fig 1.

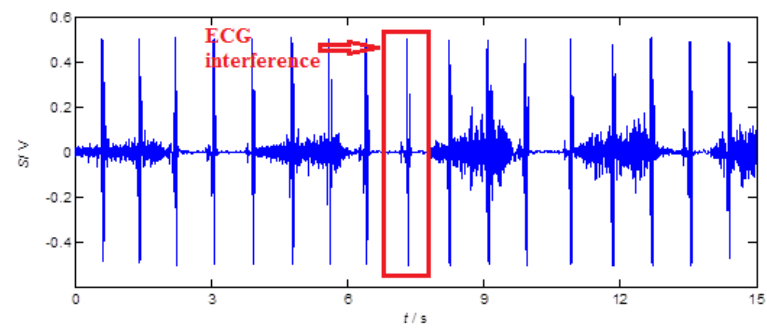

Figure 1. Raw EMGdi signal

The characteristic of noise can divide in two parts, one is that ECG interrupt has higher amplitude than EMGdi at time domain, and the other is that there has frequency overlap between EMGdi and ECG in frequency domain.

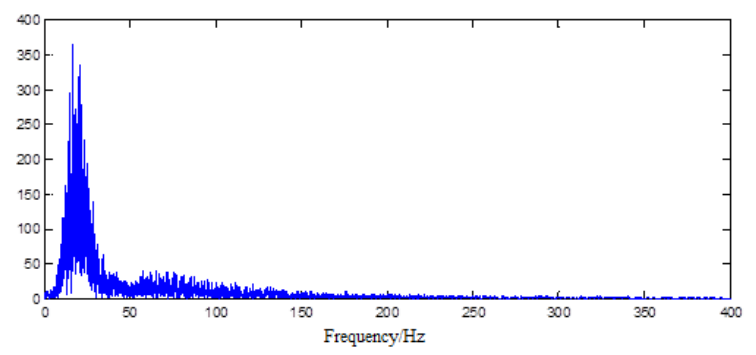

Figure 2. Power spectrum of raw EMGdi

After FFT transform, it is obvious shown in Fig.2 that the energy of contaminated EMGdi is concentrated at low frequency range from $0 \mathrm{~Hz}$ to $50 \mathrm{~Hz}$.

\section{B. Experimental Implementation}

After observing the raw EMGdi signal, we can conclude that ECG signal are concentrated in a region and its amplitude are much higher than EMGdi in time domain. 
The algorithm prepared for students can be concluded as following steps.

- $\quad$ Firstly, the peak of ECG should be located by using the knowledge point of the signal sequence.

- Secondly, after finding the position of ECG, the contaminated part of EMGdi can be extracted by using the knowledge point of array interception.

- Thirdly, ECG interference are eliminated by low pass filter by using the knowledge point of IIR filter;

- Finally, de-noised EMGdi signal is reconstructed by extraction parts and original parts.

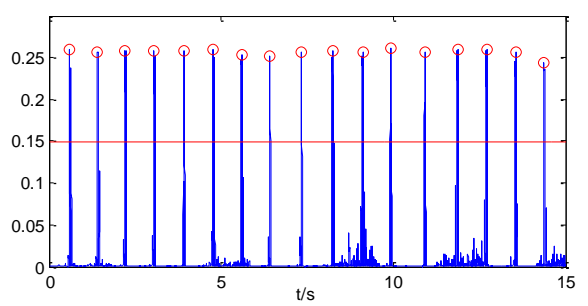

Figure 3. ECG location

The square of signal is used to search ECG interference location and determine the range of interference. The position is shown as Fig .3.

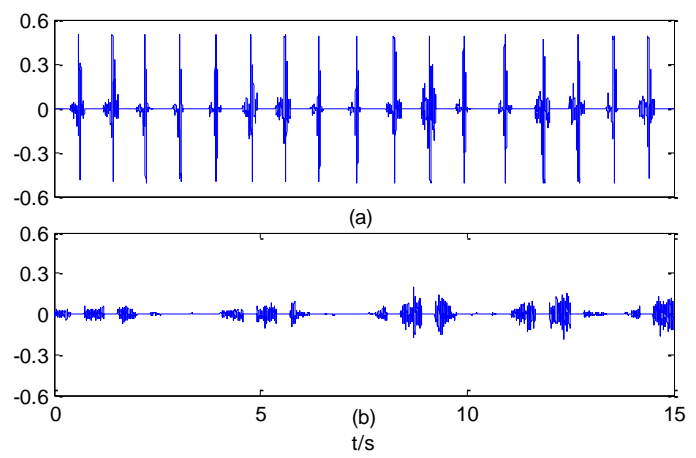

Figure 4. ECG extraction from EMGdi:(a) ECG part;(b) remain ECGdi

The contaminated part of EMGdi are extracted from raw signal just as shown in Fig.4 (a), and the remain EMGdi without any interference are shown in Fig.4 (b). Thus, the key problem left for students is how to design a filter to remove the ECG interference in contaminated part of EMGdi. In analog circuit, capacitance and resistance are the most basic components in filter design. How to transform analog filter to digital filter will throw students to for a loss. This transform building up the bridge between analog and digital is most important for engineering application, but, this knowledge point is easiest to be ignored in theory education.

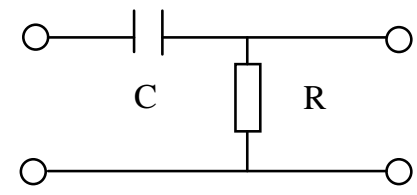

Figure 5. Analog circuit of RC filter
According to the Laplace transform, the transfer equation of Fig. 5 can be described as below

$$
\mathrm{H}(\mathrm{S})=1 /(\mathrm{SC}+\mathrm{R})
$$

The basic idea of the bilinear transformation method is to transform the analog filter into a digital filter by using numerical integration [4].

$$
\mathrm{S}=2 \times(\mathrm{Z}-1) / \mathrm{T} /(\mathrm{Z}+1)
$$

$\mathrm{T}$ is the sample interval time. Thus, (1) can be expressed as follow

$$
\mathrm{H}(\mathrm{Z})=\mathrm{T} \times(\mathrm{Z}+1) /(2 \mathrm{C}(\mathrm{Z}-1)+\mathrm{RT}(\mathrm{Z}+1))
$$

We choose that $R$ is $1 \Omega$ and the cut-off frequency is $100 \mathrm{HZ}$, after calculation, we can infer that $\mathrm{C}$ is 0.0016 . As mentioned above, $\mathrm{T}$ is $0.0005 \mathrm{~s}$.

$$
\mathrm{y}(\mathrm{n})=(0.8429 \mathrm{y}(\mathrm{n}-1)+\mathrm{x}(\mathrm{n})-\mathrm{x}(\mathrm{n}-1)) / 1.1571
$$

The sequence of $x(n)$ is input data and the sequence of $y(n)$ is output data.
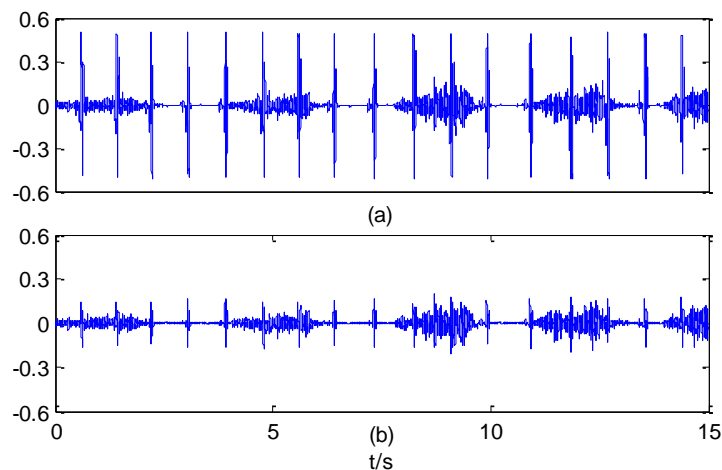

Figure 6. De-noised result:(a)EMGdi overlap ECG noise;(b) de-noising by digital filter

It can be clearly seen from the Fig.6 that the components of the electrocardiogram (ECG) interference processed by digital filter are obviously reduced.

\section{Experimental Summary}

The experimental content mentioned above is an innovative experiment in engineering education, which is widely covered knowledge points of digital signal processing and analog electronic technology. It is necessary for students to learn how to analysis the characteristic of noise and then use the filter to remove the noise. In this experiment, the most important part of digital filter is the knowledge point of bilinear transformation. It is also worth to emphasize the importance of this knowledge point for the students. 


\section{COMPREHENSIVE ASSESSMENT SYSTEM}

Taking the learning process and engineering practice goal as the guiding ideology, combining with the teaching process and teaching objective management, we build up a comprehensive evaluation system for extracurricular autonomous learning. The final grade is combined as follows: 10 points belong to PPT Presentation, 40 points belong to experimental examination, 50 points final examination.

\section{CONCLUSION}

We have systematically proposed some methods to reform the course of DSP. These methods are focused on theoretical teaching, engineering practice model in experimental teaching and comprehensive evaluation system.
Through this reform, students' learning ability is improved, and theoretical knowledge points can be applied to practical engineering signal preprocessing.

\section{REFERENCES}

[1] Zeng,Zhi, Tao,Ning, Feng,Li Chun, et al. Research in Teaching Reform of Digital Signal Processing Course[J]. Applied Mechanics \& Materials, 2013, 239-240:1645-1648.

[2] Douglas S C. The INFINITY Project: digital signal processing and digital music in high school engineering education[C]// Applications of Signal Processing to Audio and Acoustics, 2001 IEEE Workshop on the. IEEE, 2001:1-6.

[3] Jiang X, Bao Y. Digital signal processing teaching reform based on MATLAB $[\mathrm{C}] / /$ International Conference on Electronics and Optoelectronics. IEEE, 2011:V1-219-V1-221.

[4] Erfani S, Ahmadi M. A new look at digital filter realization by conformal mapping[J]. Computers \& Electrical Engineering, 1996, 22(5):353-356. 